\title{
Significance of Exercise During COVID-19 Pandemic and Social Distancing
}

\section{COVID-19 Pandemisi ve Sosyal İzolasyon Sürecinde Egzersizin Önemi}

\author{
Esma Arslan, Sabriye Ercan
}

Sports Medicine Department, Faculty of Medicine, Süleyman Demirel University, Isparta, Turkey

\author{
E. Arslan \\ 0000-0001-7097-8619 \\ S. Ercan iD \\ 0000-0001-9500-698X \\ Geliş Tarihi/Date Received: \\ 18.05.2020 \\ Kabul Tarihi/Date Accepted: \\ 18.05.2020 \\ Yayın Tarihi/Published Online: \\ 28.05.2020 \\ Yazışma Adresi / \\ Corresponding Author: \\ Esma Arslan \\ Süleyman Demirel Üniversitesi \\ Tıp Fakültesi, Spor Hekimliği \\ Anabilim Dalı, Isparta, Türkiye \\ E-mail: \\ esmaarslan.sdu@gmail.com
}

(C2020 Türkiye Spor Hekimleri Derneği. Tüm hakları saklıdır.
Yeni bir Koronavirus tipi olarak tanımlanan SARS-CoV 2 etkeni; 2019 yılının aralık ayında Çin'in Wuhan kentinde ortaya çıkmıştır (1). Bu etkenin neden olduğu COVID-19 hastalığı, kısa sürede tüm dünyayı etkisi altına almış ve Dünya Sağlık Örgütü tarafından 30 Ocak 2020'de uluslararası bir halk sağlığı acil durumu olarak ilan edilmiştir (2).

COVID-19 salgınının yayılımını azaltmak ve insanların virüs maruziyetini önlemek amacıyla çeşitli yetkililer tarafından halka evde kalmaları önerilmiştir. Dış ortam aktivitelerinin kısıtlanması, düzenli fiziksel aktivite ve egzersiz de dahil olmak üzere bireylerin rutin günlük faaliyetlerinde değişikliklere neden olmuştur (3). Uzun süre evde kalmak; dijital oyun oynama, televizyon izleme, mobil cihaz kullanma gibi hareketten yoksun davranışlara aşırı miktarda zaman harcamaya sebep olabilmektedir. Ancak, düzenli fiziksel aktivitenin azaltılması ve dolayısıyla daha düşük enerji harcanması, kronik hastalıklar için potansiyel kötüleşme riskini beraberinde getirirken, aynı zamanda kaygıya ve depresyona katkıda bulunan davranışları da artırabilmektedir (4). Üstelik, hareketsiz olarak daha fazla zaman geçirmenin, mortalite riskinde artış ile ilişkili olduğunu gösteren çalışmalar mevcuttur (5). Fakat, fiziksel aktivitenin ve egzersizin, tüm yaş grupları için vücuda çeşitli yararları vardır ve tüm bireylerin aktif bir yaşam tarzı edinmeleri önemlidir.

Yapılan çalışmalar, fiziksel aktivitenin, bağışıklık hücrelerinde artış ile bağışıklık sistemini iyileştirebileceğini göstermiştir. Bu bağlamda, vücudu virüse karşı koruyacak bağışıklık fonksiyonunun uygun fiziksel aktivite ile artırılması önem arz etmektedir. Öte yandan, farklı şiddetteki fiziksel aktivitelerin bağışıklık sistemi üzerinde farklı etkileri vardır (6). Egzersiz şiddetinin inflamatuar faktörler ve bağıșıklık hücreleri üzerindeki etkisinin gözden geçirildiği bir çalışmada, yüksek şiddetli egzersizin oksidan üretimini arttırarak bağışıklık sisteminin baskılanmasına neden olabileceği belirtilmiștir. Dolayısıyla COVID-19 ile bașa çlkma sürecinde bireylere, orta yoğunlukta ve şiddette egzersiz önerilmesi gerektiği sonucuna varılmıştır (7). 
COVID-19 pandemisinde elde edilen bilgilere dayanarak; yaşlı, hipertansif, diyabetik, solunum yolları ve kardiyovasküler sistem hastalığı olan bireyler söz konusu virüs enfeksiyonu açısından daha riskli gruplar olarak tanımlanmıştır. Enfeksiyonun hızlı yayılımını durdurmak için tecrit uygulaması en iyi seçenek gibi görünmesine rağmen, bu sürecin sosyal izolasyona alınan hastaların sağlığının fiziksel ve zihinsel boyutları üzerinde çeşitli etkileri olabileceği göz ardı edilmemelidir $(1,8)$. Sağlığın korunabilmesi ve geliştirilmesi için COVID-19 enfeksiyonu açısından riskli gruplar olarak tanımlanan geriatrik popülasyonun ve kronik hastalığa sahip yetişkinlerin de evde geçirilen süreçte hareketsiz kalmamalarının sağlanması önemlidir.

Daha hareketli bir yaşama geçilebilmesi için planlanan bireysel egzersiz programlarının genel özellikleri bulunmaktadır. Bunlardan biri, kişinin fiziksel uygunluk parametrelerinin her birine uygun şekilde müdahale edilmesidir. Fiziksel uygunluk parametreleri doğrultusunda planlanacak programın içeriğini; aerobik/dayanıklılık, direnç/güç, denge ve esneklik egzersizleri olarak dört ana kategoride sinıflayabilmek mümkündür (9).

Bireysel egzersiz programında yer alması gereken ilk egzersiz tipi olan aerobik egzersizler esnasında, geniş kas gruplarının belirli bir düzende hareket etmesiyle kardiyovasküler dayanıklılık elde edilmektedir. Aerobik egzersizin vücut yağ oranını azaltıcı etkisi mevcuttur. Aerobik egzersizin yapılması, kas liflerinin kesitsel alanındaki ve enzim aktivitesindeki artışı ile yaștan bağımsız olarak kas yapısında düzelme sağlamaktadır (10). Direnç egzersizleri, kas kitlesinde artış sağlamanın yanı sıra, sıklıkla ileri yaştaki bireylerin sağlık sorunu olan osteoporozla mücadelede de etkindir. Bu egzersiz tipi hem kadınlarda hem de erkeklerde kemik mineral yoğunluğunu iyileştirmek için etkilidir. Direnç egzersizlerinin, yürüme vb. gibi aerobik egzersizle kombine edilmesi kemik mineral yoğunluğunu koruma ve artırmada daha etkili sonuçlar almamızı sağlamaktadır (11). Diğer taraftan aktivenin azalması ve yaşın ilerlemesi, eklem esnekliğinin kaybolmasına neden olabilmektedir. Eklem esnekliği azalmış bireyler, bir raftaki eşyalara ulaşma, giyinme gibi basit günlük aktiviteleri gerçekleştirmede bile zorluk yaşayabilmektedir. Egzersiz reçetesinde esneklik egzersizlerine yer verilmesi, eklem hareket açıklığını geliştirerek yaşam kalitesinin artırılmasına katkıda bulunmaktadır (12). Denge egzersizleri ise vücudun/eklemlerin uzaydaki konumunun algılanmasina, eklem pozisyon hissinin arttırılmasına ve koordinasyonun sağlanmasına katkı sağlamaktadır. Denge egzersizi yapılması ile birlikte fiziksel fonksiyonlarda iyileşme sağlanmakta, denge fonksiyonları geri kazanılmakta ve düşme riski azaltılabilmektedir (12). Kişilerin sağlık durumu, önerilen hedeflere ulaşılmasını engellese bile, 'az da olsa herhangi bir fiziksel aktivitede bulunmak, hareketsiz olmaktan çok daha iyidir' prensibini benimsemek gereklidir (13).

Tüm bu durumlar göz önünde bulundurulduğunda, COVID-19 pandemisi ile mücadele ettiğimiz bugünlerde evde ve kontrollü sosyal hayatta aktif bir yaşam tarzını sürdürmek ana hedef olmalıdır. Genellikle spor salonlarında ve açık hava etkinliklerinde daha fazla altyapı ve alternatif olduğu düşünülse de sanılanın aksine evde kalma sürecinde egzersiz yapmak için birçok olanak mevcuttur.

Amerikan Spor Hekimleri Birliği ve Dünya Sağlık Örgütü, sağlı̆̆ın korunması için tüm yetişkinlerin haftada en az 150 dakika orta şiddette aerobik aktivite ve haftada iki veya daha fazla (ardışık olmayan) gün, 8-10 büyük kas grubunu içeren 8-12 tekrarlı direnç eğitimi yapmasını önermektedir (9). Esneklik egzersizleri, haftada iki gün, günde 10 dakika boyunca, her büyük kas grubu için 15-60 saniye uygulanmalıdır. Denge ve nöromüsküler eğitim uygulamaları, özellikle düşme riski yüksek olan bireylerde düşmeleri önlemek için egzersizin bir parçası olmalıdır. Evde yapılan denge egzersizleri yastık, minder gibi yumuşak zemin üzerinde; çift ayak, gözler açık ve kapalı; tek 
ayak, gözler açık ve kapalı șekilde kademeli olarak zorlaştırılarak uygulanabilmektedir. Egzersiz sırasında düşme riskini en aza indirgemek için, denge eğitimi ilk başta yakından denetlenmeli, eğitime daha az zorlayıcı duruşlarla başlanmalı ve eğitim kademeli olarak ilerletilmelidir.

Bireysel fiziksel aktivite planlarında aktivitenin sıklığı, şiddeti ve yoğunluğu (süresi) mutlaka belirlenmeli, planda kisa ve uzun vadeli hedefler oluşturulmalıdır. Egzersize yeni başlayacak bireyler için planlanan programın başlangıcında, fiziksel aktivitenin şiddeti ve süresi düşük olmalıdır. Egzersize uyum sağlandıkça kademeli ve yavaş bir şekilde artırılmalıdır. Fiziksel aktivite programına makul sınırlar çizilmeli, programa ulaşılabilir hedefler ve kişiye uyan aktivitelerle başlanmalıdır. Aktiviteler, günlük yaşam aktivitelerinden (örneğin, merdiven çıkma, yürüme) ya da fiziksel uygunluğu geliştirme veya sürdürme için yapılandırılmış, tekrarlayan hareketlerden (örneğin; ağırlık kaldırma ya da direnç lastiği egzersizleri) oluşmalıdır (9). Ev içinde yürüyüş yapmak, gerekli ise koruyucu önlemleri alarak (maske vb. takarak) markete yürüyerek gitmek, çeşitli ağırlıklar kaldırmak ve taşımak, merdiven çıkmak, sandalyeye oturup kalkmak, lunge (adımlama), squat (çömelme), mekik, şınav, yoga, pilates gibi az alana ve ekipmana ihtiyaç duyulan, her yerde ve zamanda uygulanabilen egzersizler ev içinde ve sosyal izolasyon şartlarında yapılabilecek egzersizlere örnek olarak sayılabilmektedir.

Fiziksel aktiviteyi yapmanın yanında aktivitenin takibi de önemli ve gereklidir. Bu amaçla sosyal izolasyon sürecinde de pedometre kullanılabilmektedir. Pedometre kullanımının, kişisel bir adım hedefi belirlendiğinde fiziksel aktiviteyi önemli ölçüde arttırdığı gösterilmiştir (14). Ayrıca; internet, mobil teknolojiler ve televizyon aracılığıyla fiziksel aktiviteyi teşvik etmeye ve sunmaya odaklanan e-Sağlık uygulamaları ve egzersiz videolarının kullanımı, bu kritik dönemde fiziksel işlevi ve zihinsel sağlığı sürdürmenin diğer geçerli yollarıdır (15).
COVID-19 salginı sirasinda insanların hareketlerini kısitlayan idari tedbirler, fiziksel aktivitenin sinırlı olması veya tüm egzersiz biçimlerinin tamamen ortadan kaldırılması gerektiği anlamına gelmemelidir, bu süreçte ev içerisinde de aktif olmaya özen gösterilmelidir (15). Egzersizin fiziksel uygunluğu, iyilik halini, motivasyon düzeyini ve bağışıklığı güçlendirici etkisinden yararlanmak için evde de fiziksel aktivitenin sürdürülmesi gerektiğini gösteren güçlü gerekçeler vardır. Fiziksel aktivite ve egzersiz yapmak için spor salonu ve çeşitli ekipmanların olması şart değildir. Yürüme, bahçe işleri ve temizlik gibi günlük aktiviteler zindeliği ve genel sağlığı geliştirebilmektedir. İçerisinde bulunduğumuz bu sosyal izolasyon zamanını, bir egzersiz programına başlamak için fırsat olarak kullanan kişiler için amaç, hayat "normale" döndüğünde de egzersiz yapmaya devam etmek olmalıdır (16).

Sonuç olarak, pandemi sürecini en az hasarla atlatabilmek için evde hareketli kalmaya çalışılmalıdır. Kişisel özellikler dikkate alınarak planlanan egzersiz programlarını hayatın bir parçası haline getirmek, sağlığı her yönüyle koruyup geliştirecek bütüncül etkiler sağlayacaktır.

Available at: http://journalofsportsmedicine.org and http://dx.doi.org/10.5152/tjsm.2020.190

Cite this article as: Arslan E, Ercan S. Significance of exercise during COVID-19 pandemic and social distancing. Turk J Sports Med. 2020;55(2):188-91.

\section{Conflict of Interest}

The authors declared no conflicts of interest with respect to the authorship and/or publication of this article.

\section{REFERENCES}

1. Jiménez-Pavón D, Carbonell-Baeza A, Lavie, CJ. Physical exercise as therapy to fight against the mental and physical consequences of COVID-19 quarantine: Special focus in older people. Prog Cardiovasc Dis. 2020. DOI: 10.1016/j.pcad.2020.03.009

2. https://www.who.int/news-room/detail/30-012020-statement-on-the-second-meeting-of-theinternational-health-regulations-(2005)-emergencycommittee-regarding-the-outbreak-of-novelcoronavirus-(2019-ncov) Erişim tarihi: 14.05.2020 
3. Chen P, Mao L, Nassis GP, Harmer P, Ainsworth BE, Li F. Coronavirus disease (COVID-19): The need to maintain regular physical activity while taking precautions. J Sport Health Sci. 2020; 9 (2): 103-4.

4. Owen N, Sparling PB, Healy GN, Dunstan DW, Matthews CE. Sedentary behavior: emerging evidence for a new health risk. Mayo Clin Proc. 2010; 85 (12): 1138-41.

5. Ensrud KE, Blackwell TL, Cauley JA, Dam TTL, Cawthon PM, Schousboe JT, et al. Objective measures of activity level and mortality in older men. $\mathrm{J} \mathrm{Am}$ Geriatr Soc. 2014; 62(11): 2079-87.

6. Nieman DC, Wentz LM. The compelling link between physical activity and the body's defense system. $J$ Sport Health Sci. 2019; 8(3): 201-17.

7. Rahmati-Ahmadabad S, Hosseini F. Exercise against SARS-CoV-2 (COVID-19): Does workout intensity matter? (A mini review of some indirect evidence related to obesity). Obes Med. 2020; 100245 . DOI: 10.1016/j.obmed.2020.100245

8. Fletcher GF, Landolfo C, Niebauer J, Ozemek C, Arena R, Lavie CJ. Promoting physical activity and exercise: JACC health promotion series. J Am Coll Cardiol. 2018; 72(14): 1622-39.

9. Chodzko-Zajko WJ, Proctor DN, Singh MAF, Minson CT, Nigg CR, Salem GJ, et al. Exercise and physical activity for older adults. Med Sci Sport Exer. 2009; 41(7): 1510-30.
10. Roubenoff R. Sarcopenia and it simplications for the elderly. Eur J Clin Nutr. 2000; 54(3): 40-7.

11. Bolam KA, Van Uffelen JG, Taaffe DR. The effect of physical exercise on bone density in middle-aged and older men: a systematic review. Osteoporosis Int. 2013; 24(11): 2749-62.

12. Lee PG, Jackson EA, Richardson CR. Exercise prescriptions in older adults. Am Fam Physician. 2017; 95(7): 425-32.

13. Lee PG, Cigolle CT, Ha J, Min L, Murphy SL, Blaum CS, et al. Physical function limitations among middle-aged and older adults with prediabetes: one exercise prescription may not fit all. Diabetes Care. 2013; 36(10): 3076-83.

14. Bravata DM, Smith-Spangler C, Sundaram V, Gienger $\mathrm{AL}$, Lin $\mathrm{N}$, Lewis $\mathrm{R}$, et al. Using pedometers to increase physical activity and improve health: a systematic review. JAMA. 2007; 298(19): 2296-304.

15. Tate DF, Lyons EJ, Valle CG. High-tech tools for exercise motivation: use and role of technologies such as the internet, mobile applications, social media, and video games. Diabetes Spectr. 2015; 28(1): 45-54.

16. Nyenhuis SM, Greiwe J, Zeiger JS, Nanda A, Cooke A. Exercise and Fitness in the age of social distancing during the COVID-19 Pandemic. J Allergy Clin Immunol Pract. 2020. DOI: 10.1016/j.jaip.2020.04.039 